ИЗВЕСТИЯ АКАДЕМИИ НАУК ЭСТОНСКОИ ССР. ТОМ 19 ХИМИЯ * ГЕОЛОГИЯ. 1970, № 4

\title{
РЭЭТ МЯННИЛЬ
}

\section{ВЕРХНЕЛЛАНДОВЕРИЙСКИЕ ФАКОПИДЫ (TRILOBITA) ЭСТОНИи}

Настоящая статья является продолжением предыдущей статьи автора (Мянниль, 1970), в которой рассмотрены нижне- и среднелландоверийские факопиды. В данной статье кроме описаний двух видов из адавереского горизонта, даны краткий обзор о распространении и развитии представителей факопид во всем разрезе лландовери Эстонии и сравнение эстонских видов со скандинавскими. В качестве сравнительного материала автор имел возможность изучать факопиды из коллекции Швед亡кого государственного музея [в том числе и Pterygometopidella quadrilineata (Ang.)], высланные д-ром В. Яануссоном, а также специально выполненные им для нас фотоснимки Acernaspis elliptifrons (Esm.) из типового местонахождения. Автор выражает доктору В. Яануссону искреннюю благодарность за любезно предоставленный им материал.

Перед фотографированием экземпляры покрывались хлористым аммонием. Фотографии выполнены автором. Описанный материал хранится в фондах Геологического музел Института геологии АН ЭССР в Таллине.

\section{Семейство PHACOPIDAE Hawle et Corda, 1847 Подсемейство РНACOPINAE Hawle et Corda, 1847 Род Acernaspis Campbell, 1967}

Acernaspis? konoverensis sp. $\mathrm{n}$.

(Табл. I, фиг. $1-9$ )

Голотип. Головной щит, $\operatorname{Tr} 2458$ a. Верхний лландовери, адавереский горизонт (Н). Река Коновере, дер. Лятикюла.

М а те ри ал. 4 полных экземпляра, 30 головных щитов, одна гипостома, 6 хвостовых щитов. Сохранность хорошая.

О п и с а н и е. Головной щит выпуклый, с широкоокругленным передним и слабовогнутым задним краями. Глабель опускается круто, почти вертикально (но не нависая) перед глазом. Спинные борозды узкие, неглубокие и расходятся под углом около $50^{\circ}$, слегка изгибаясь наружу.

Борфзды глабели, кроме задних, очень слабые и не соприкасающиеся со спинными бороздами. Дистальная ветвь передней борозды прямая, начинается вблизи переднего края глаза и направлена назад под небольшим углом к спинной борозде. Проксимальная ветвь передней борозды вогнута назад. Средняя борозда глабели вогнута очень слабо и располагается почти перпендикулярно к спинной борозде. Задняя борозда гла- 
бєли глубокая, после поворота вперед выражена слабо. Затылочная борозда в средней своей части слабая, к концам становится глубокой. Промежуточное кольцо кончается четкими бугорками, отделенными от средней части кольца короткими бороздами. Затылочное кольцо умеренной ширины (в продольном сечении), приподнимается несколько выше глабели. Глаза большие, протягиваются от передних боковых углов глабели почти до задней краевой каймы. Глазные крышки равномернодугообразные, широкие и высокие, приподнятые до уровня глабели или почти до нее. Пальпебральные борозды очень слабые, заметно выражены только у своих концов. Зрительная поверхность почти вертикальная, имеет у изученного материала 76 -89 (чаще всего 87) глазных линз. Линзы расположены в 17 вертикальных рядах, состоящих из 2-6 линз (лишь изредка наблюдается 7 линз) каждый. Количество линз по вертикальным рядам, начиная спереди, чаще всего следующее: 45666666656655432 . Количество линз в разных глазах у одного и того же экземпляра часто не ссвпадает (различается на единицу). Большое количество линз (88 и 89$)$ встретилось лишь в одном случае, причем у головного щита средних размеров. Среди изученного материала имеется только один явно молодой экземпляр с длиной головного щита 5 мм. У него насчитывается лишь 76 глазных линз, из которых несколько нижних очень маленькие, эллиптической формы. В остальных экземплярах нижние линзы лишь изредка имеют отклоняющиеся от нормы размеры. На этом основании можно предположить, что все изученные экземпляры более или менее зрелые и разное количество линз в их глазах связано с индивидуальной изменчивостью. Новые линзы при увеличений их общего числа возникают только у нижних концов 11 средних рядов; мелкие недоразвитые линзочки, наблюдаемые у верхних концов в 5 и 12-м рядах, сформировались уже на молодой стадии развития особи (см. также Clarkson, 1966).

Лицевые швы образуют на щечном поле нерезкий изгиб и соединяются перед глабелью в виде очень слабого заострения.

Щеки широкие (в поперечном сечении), с округленными углами, снабженными мелкими шипами. Передняя краевая кайма неразвита. Боковая и задняя краевые каймы выражены слабо, расширяясь и ослабляясь на щечных углах. Задняя краевая борозда короткая, разделяет неподвижную щеку на две неравные по ширине части (в продольном сечении), из которых задняя часть значительно шире передней.

Дублюра слабо нзгибается вниз. Субкранидиальный желоб отмечается лишь по бокам дублюры, имеет 8 зазубрин. Гипостомальный шов загнут назад.

Гипостома умеренно выпуклая, по очертанию приближается к треугольнику (рис. 1). Лопасти и каймы по рельефу не выделяются. Передний край более или менее лпямой. На заднем краю встречается три заострения. Макулы нечеткие, выражены в виде слабых желобков на передней части типостомы, расположены под углом около $45^{\circ} \mathrm{K}$ ее оси.

Туловище умеренно выпуклое, количество сегментов 11. Кольца

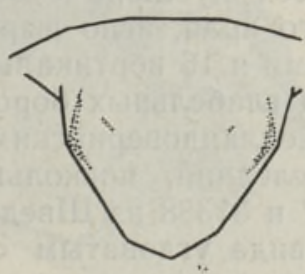

a

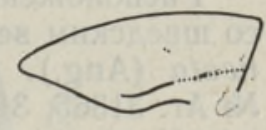

$\sigma$

Рис. 1. Acernaspis? konoverensis sp. n. Гипостома $(\times 5,3)$ : a - сверху; $6-$ сбоку рахиса довольно широкие и уплощенные. Борозды между кольцами и сочленовными полукольцами низкие. Плевральные борозды также неглу- 
бокие и протягиваются немного меньше, чем на половину длины плевры (в поперечном сечении). Задние части окончаний у $6-7$ задних плевр прямоугольные, спереди они постепенно становятся округленными.

Хвостовой щит имеет расширенно-полукруглое очертание. Средняя часть его заднего края более или менее прямолинейная. Рахис умеренно выпуклый, протягивается приблизительно на $3 / 4$ длины пигидия, немного суживается к округленному концу. Рахис состоит из 7-8 колец, из которых более или менее четко выражены первые 5-6, остальные кольца нерасчлененные. На задних краях колец рахиса развиты небольшие дугообразные вырезки. На плевральной лопасти имеется три очень слабо выраженные плевральные борозды, которые доходят приблизительно до половины ширины лопасти.

Поверхность всего спинного щита и дублюры тонкозернистая.

Таблица $I$

Размеры некоторых экземпляров вида A.? konoverensis sp. n., м.

\begin{tabular}{|c|c|c|c|c|}
\hline & $\underset{2458 \mathrm{a}}{\operatorname{Tr}}$ & $\begin{array}{c}\operatorname{Tr} \\
2459\end{array}$ & $\begin{array}{c}\operatorname{Tr} \\
2464\end{array}$ & $\begin{array}{c}\mathrm{Tr} \\
2462\end{array}$ \\
\hline Длина спинного щита & & 23,0 & 22,0 & \\
\hline Длина головного щита & 7,0 & 7,0 & 5,5 & 7,2 \\
\hline Ширина головного щита & 13,0 & 11,2 & 9,5 & 13,0 \\
\hline Длина глабели & 5,8 & 5,7 & 4,8 & 5,8 \\
\hline Ширина глабели спереди & 6,0 & 6,0 & 5,0 & 6,4 \\
\hline Ширина глабели у основания & 3,4 & 3,3 & 2,8 & 3,5 \\
\hline Угол спинных борозд & $48^{\circ}$ & $52^{\circ}$ & $\sim 50^{\circ}$ & $48^{\circ}$ \\
\hline Длина глаза (вверху) & 3,1 & 3,0 & 2,6 & 3,4 \\
\hline Высота зрительной поверхности & 2,1 & 2,1 & 1,6 & 2,1 . \\
\hline Количество глазных линз & $84 ; 85$ & 83 & & 87 \\
\hline Длина туловища & & 12,0 & 12,0 & \\
\hline Ширина туловища & & 15,0 & 9,0 & \\
\hline Ширина рахиса & & 4,0 & 3,3 & \\
\hline Длина хвостового щита & & 4,0 & 4,0 & \\
\hline Ширина хвостового щита & & 8,2 & 6,8 & \\
\hline Длина рахиса & & 3,2 & 3,0 & \\
\hline Ширина рахиса спереди & & 2,6 & 1,8 & \\
\hline Ширина рахиса у конца & & 1,4 & 1,4 & \\
\hline
\end{tabular}

С р в н е н и е. Расположением глаз, глабельных борозд и вертикальным опусканием передней части глабели описываемый внд сходен сAcernaspis orestes (Billings). Последний отличается от $A$. ? konoverensis выраженным по всей дублюре субкранидиальным желобом, округлым очертанием лобного края, ясно выраженными пальнебральными и глабельными бороздами и 16 вертикальными рядами глазных линз.

Расположением глабельных борозд A.? konoverensis сходен также со шведским верхнелландоверийским видом Pterygometopidella quadrilineata (Ang.). Последний, поскольку можно судить по экземплярам № Ar. 31365,31387 и 31388 из Шведского государственного музея, отличается от нашего вида угловатым очертанием лобного края, пологим падением глабели, удлиненными щеками, более четкими боковой краево́й каймой и пальпебральными бороздами, 16 вертикальными рядами глазных линз и относительно длинным хвостовым щитом. Строение дублюры. у указанных экземпляров неизвестно.

На основании общего сходства с $P$. quadrilineata не исключена возможность, что A.? konoverensis относится к роду Pterygometopidella, однако, поскольку типовой вид этого рода недостаточно изучен и диагно- 

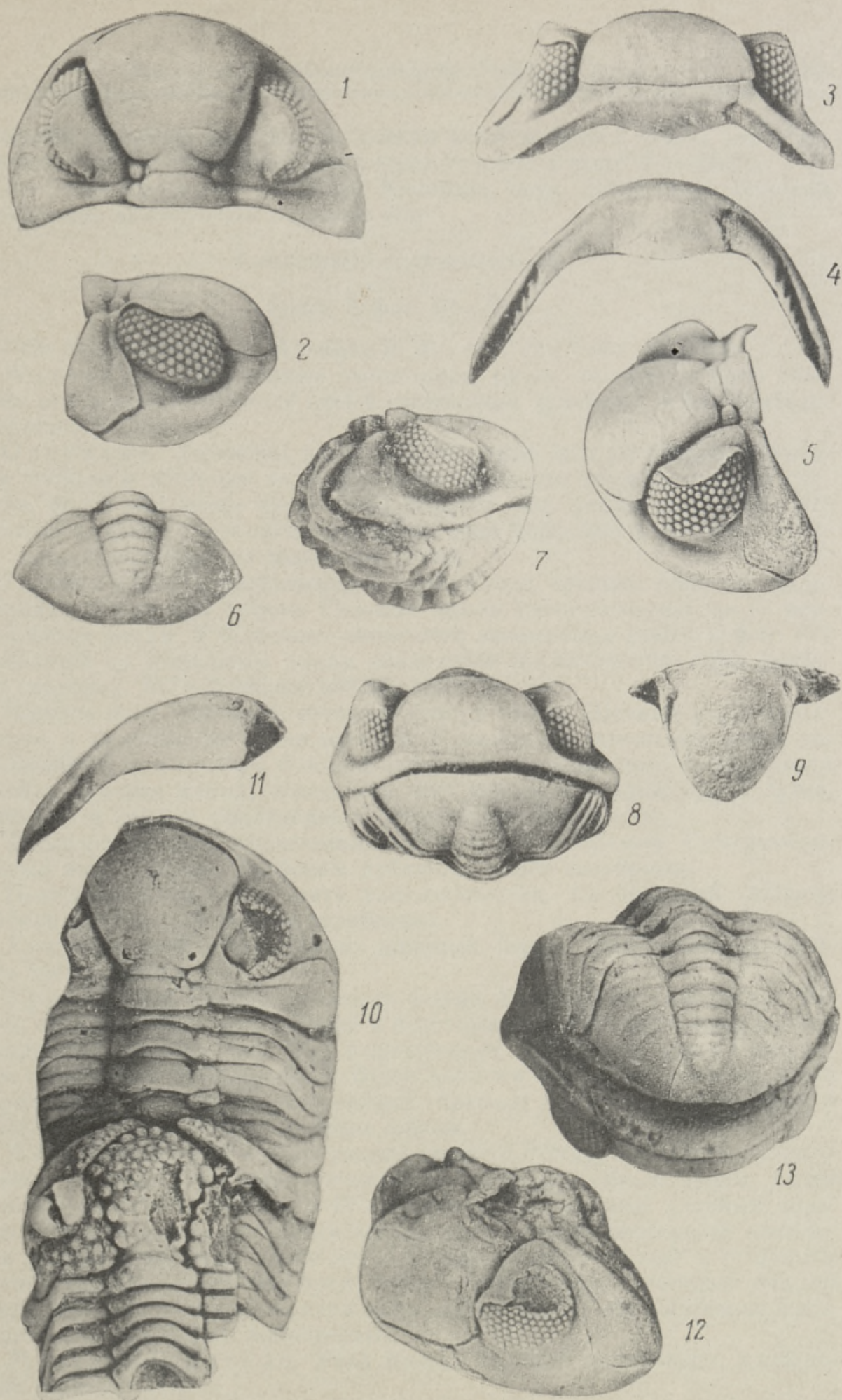

Таблица I

Фиг. 1-9. Acernaspis? konoverensis sp. п. $\times$ 4. Река Коновере, дер. Лятикюла, Н. $1-5$ - голотип, головной щит, $\operatorname{Tr} 2458 \mathrm{a}: 1$ - вид сверху; 2 - вид сбоку; 3 - вид спереди; 4 - вид снизу; 5 - вид на щечное поле; 6 - хвостовой щит, $\operatorname{Tr} 2460$, вид сверху; 7-8- полный свернутый экземпляр, Tr $2465: 7$ - вид сбоку; 8 - вид спереди; 9 - гипостома, $\operatorname{Tr} 2453$, вид сверху.

Фиг. 10-13. Acernaspis? cf. konoverensis. 10 - неполный головной щит и туловише вместе с Encrinurus rumbaensis Rosenstein, $\operatorname{Tr} 1814, \times 4$, р. Валгу, $\mathrm{H} ; 11$ - то же, вид снизу; 12-13 - полный свернутый экземпляр, $\operatorname{Tr} 1961$, ×3, р. Валгу, Н: 12 - вид на щечное поле; 13 - вид на пигидии. 

стические признаки рода еще не совсем ясны, в данной статье мы относим наши верхнелландоверийские виды условно к роду Acernaspis.

Местон ахождение. Река Коновере, дер. Лятикюла. Верхний: лландовери, адавереский горизонт (Н).

\section{Acernaspis? cf. konoverensis}

(табл. I, фиг. 10-13)

1958 Eophacops ń. sp. Мянниль Р. М., стр. 211, табл. VII, фиг. 7.

М а тери ал. Два полных экземпляра (один молодой), один частично отломанный головной щит с сегментами туловища и две глабели. Сохранность средняя.

О п и с а н и. Умеренно выпуклый головной щит со слегка угловатым лобным и вогнутым задним краями. Спинные борозды узкие и глубокие, более или менее прямые, расходятся под углом около $45-50^{\circ}$. Борозды глабели располагаются аналогично бороздам у A.? konoverensis. Затылочная борозда выражена четко.

Глазные крышки равномерно дугообразные, средней ширины; пальпебральные борозды четкие. Глазные линзы располагаются по 17 вертикальным рядам. У большого свернутого экземпляра (табл. I, фиг. 12) отмечается по отдельным рядам следующее расположение линз (начиная спереди): 56767666666665432 ; всего их 93.

Щечное поле удлинено, оттянуто слегка назад. Щечные углы округленные, с мелкими щечными шипами. У молодого экземпляра щеки заканчиваются под прямым углом. В передней части щечного поля развита боковая краевая кайма, вследствие чего между передним краем глаза, глабелью и каймой образовалось треугольное углубление.

Дублюра ровная, гипостомальный шов почти прямой. Субкранидиальный желоб развит по бокам дублюры, имеет зазубрины.

Поверхность спинного щита тонкозернистая, на передней лопасти глабели отмечаются мелкие углубления.

Хвостовой щит относительно длинный, имеет очертание округленного трєугольника.

С р а в н ен и е. Рассматриваемая форма по строению глабельных борозд, субкранидиального желоба и некоторым другим признакам сходна. с видом A.? konoverensis. Она отличается от последнего слегка угловатым очертанием лобного края, более пологим падением глабели, четче выраженной боковой краевой каймой, прямым гипостомальным швом и относительно длинным хвостовым щитом.

A.? cf. konoverensis весьма сходна также с Pterygometopidella quadrilineata, отличаясь от него относительно прямым лобным краем, более пологим падением глабели и 17 вертикальными рядами глазных линз. Описываемая форма, по-видимому, по своим морфологическим признакам занимает промежуточное место между $A$.? konoverensis и $P$. quadrilineata. Возможно, что она представляет собой самостоятельный вид, но ввиду недостаточного материала мы в данной статье обозначаем ее предварительно как $A$.? cf, konoverensis.

Местонахождение. Река Валгу. Верхний лландовери, адавереский горизонт $(\mathrm{H})$.

К настоящему времени из лландовери Эстонии известно шесть видов факопид, представленных в нашей коллекции остатками удовлетворительной сохранности и описанных как самостоятельные виды в преды- 
дущей и данной статьях автора. Остальные формы, вероятно, представляют собой отчасти также самостоятельные виды, но могут быть описаны в качестве таковых лишь в случае нахождения экземпляров лучшей сохранности.

Большинство изученных видов распространено в глинистых отложениях лландовери в Южной и Средней Эстонии и найдено только в кернах буровых скважин. Из обнажения глинистой фации происходит лишь A.? konoverensis. В карбонатных отложениях представители факопид встречаются еще реже: здесь установлены лишь Acernaspis sp. а и A.? cf. konoverensis.

Факопиды прослеживаются в Эстонии от низов нижнего лландовери (табл. 2) до нижней части венлока включительно. Отдельных-их представителей, очевидно, можно приурочить к определенным стратиграфическим уровням, соответствующим мелким подразделениям горизонтов. Это говорит о быстрых темпах эволюции факопид в лландовери и об их значении для стратиграфии. Последнее, однако, ограничено сравнительной редкостью их находок.

В течение лландоверийского века у эстонских факопид проявляется оп-

Распространение видов рода Acernaspis в лландовери Эстонии

\begin{tabular}{l|l|l|l}
\hline & $\mathrm{G}_{1-2}$ & $\mathrm{G}_{3}$ & $\mathrm{H}$ \\
\hline & & \\
\hline Acernaspis sulcata Männil & $\times$ & & \\
A. estonica Männil & & \\
A. semicircularis Männil & $\times$ & & \\
A. sp. a & $\times$ & & \\
A. sp. b & & $\times$ & \\
A. rectifrons Männil & & $\times$ & $\times$ \\
A. incerta Männil & & \\
A. ? konoverensis sp. n. & & \\
A. ? cf. konoverensis & &
\end{tabular}
ределенная направленность в развитии, выражающаяся в следующих признаках.

Все раннелландоверийские формы имеют четко выраженный субкранидиальный желоб в передней части головного щита, дистальные ветви передних борозд глабели образуют со спинной бороздой угол около $45^{\circ}$, щечные углы острые (рис. $2, a, \delta, в)$. У форм с самого конца раннего лландовери и среднего лландовери субкранидиальный желоб в осевой части головного щита становится едва заметным, а дистальные ветви передних борозд глабели, поскольку можно судить по среднелландоверийскому виду A. incerta, образуют со спинной бороздой угол в $30-40^{\circ}$ (рис. $2,2, \partial$ ). У позднелландоверийских видов субкранидиальный желоб развит только по бокам дублюры, дистальные ветви передних борозд глабели почти параллельны спинным бороздам, щечные углы округлены и снабжены лишь мелкими зачаточными шипами (рис. $2, e$ ).

Из нижней части венлока Эстонии известен только один еще не описанный вид, который отличается от всех лландоверийских крупнымі глазами, задним расположением борозд глабели, весьма короткими дистальными ветвями передних борозд глабели, расположенными параллельно к спинным бороздам, и некоторыми другими признаками. Возможно, что этот вид не принадлежит к роду Acernaspis, но он проявляет ту же самую тенденцию развития, которая наблюдается у лландоверийских факопид.

Известные к настоящему времени эстонские лландоверийские факопиды как по морфологическим признакам, так и по возрасту можно отнести к роду Acernaspis Campbell, 1967. Только у верхнелландоверийских видов $A$.? konoverensis и $A$.? cf. konoverensis отсутствует один из 

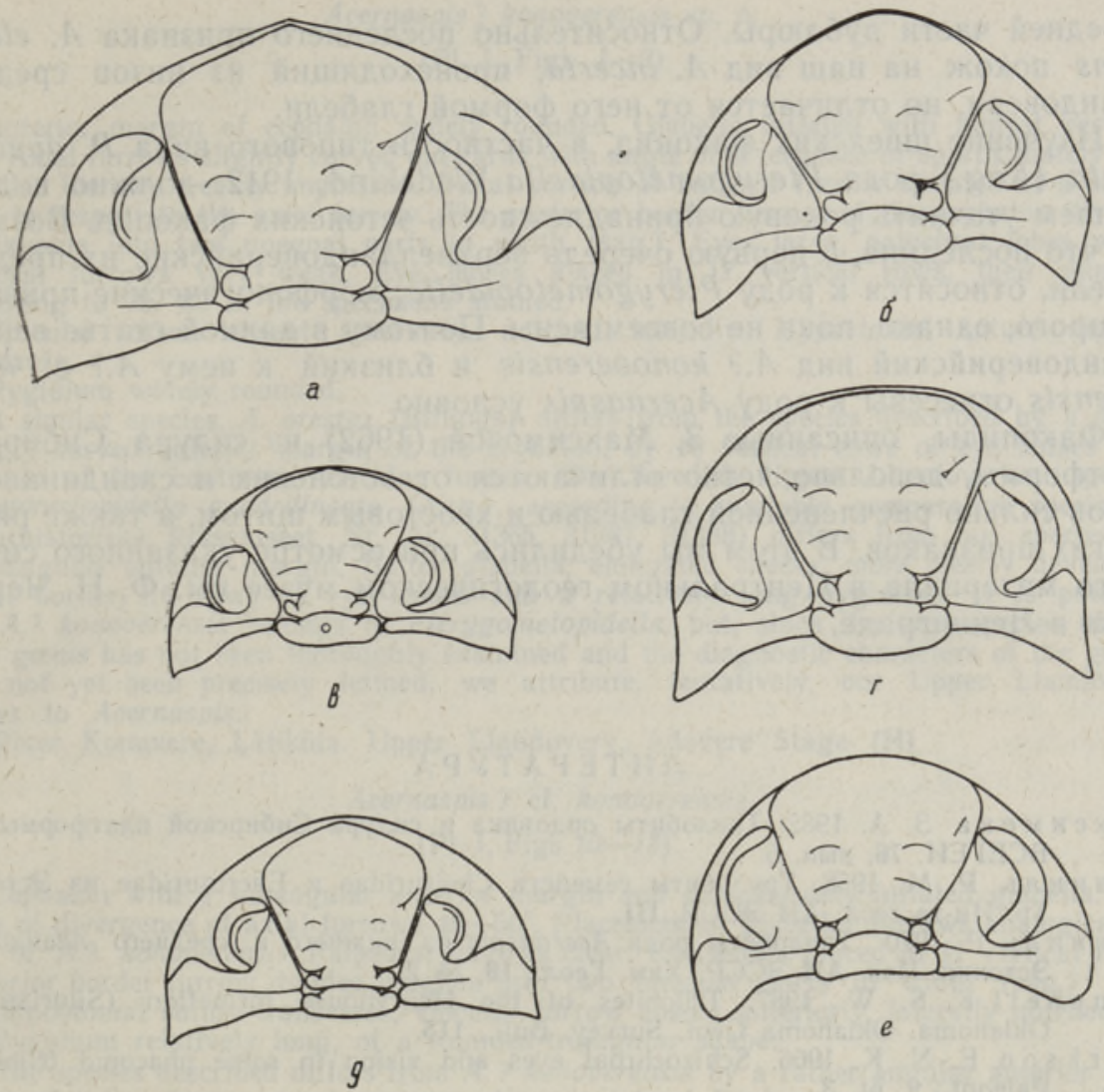

Рнс. 2. Схематический рисунок головных щитов у видов рода Acernaspis из лландовери Әстонии $(\times 5,1-5,5)$;

$a-A$. sulcata Månnil; $6-A$. estonica Männil; $B-A$. semicircularis Mănnil; e - A. rectifrons Mắnnil; $\partial-A$. incerta Männil; $e-A$.? konoverensis sp. $\mathrm{n}$.

диагностических признаков данного рода - субкранидиальный желоб в передней части головного щита.

Род Murphycops Lesperance, 1968 характеризуется также отсутствием субкранидиального желоба в передней части дублюры (по бокам желоб имеет зазубрины) и вертикальным опусканием передней части глабели, но на основании единственного известного его представителя (M. skidmorei Lesp.) данный род четко отличается от наших видов узкой дублюрой, загнутым вперед гипостомальным швом, расположением боковых борозд глабели, хорошо выраженной на всем своем протяжении боковой краевой бороздой и другими признаками.

Из других представителей лландоверийских факопид к эстонским видам близко стоят скандинавские виды Acernaspis elliptifrons (Esm.) и Pterygometopidella quadrilineata (Ang.). Образцы норвежского раннелландоверийского вида $A$. elliptifrons хорошей сохранности, видимо, вообще отсутствуют. По литературным данным (Störmer, 1940; Campbell, 1967) и фотографиям, выполненным доктором В. Яануссоном по топотипическому материалу, этот вид отличается от наших раннелландоверийских форм прежде всего эллиптическим очертанием глабели и очень слабым развитием или даже отсутствием субкранидиального желоба в 
передней части дублюры. Относительно последнего признака A. elliptifrons похож на наш вид $A$. incerta, происходящий из низов среднего лландовери, но отличается от него формой глабели.

Изучение шведских факопид, в частности типового вида $P$. quadrilineata (Ang.) рода Pterygometopidella Wedekind, 1912, должно в дальнейшем уточнить родовую принадлежность эстонских факопид. Возможно, что последние, в первую очередь верхнелландоверийские их представители, относятся к роду Pterygometopidella, морфологические признаки которого, однако, пока не совсем ясны. Поэтому в данной статье верхнелландоверийский вид $A$.? konoverensis и близкий к нему A.? cf. konoverensis отнесены к роду Acernaspis условно.

Факопиды, описанные З. Максимовой (1962) из силура Сибирской платформы, довольно четко отличаются от эстонских и скандинавских видов сильно расчлененной глабелью и хвостовым щитом, а также рядом других признаков. В этом мы убедились при осмотре указанного сибирского материала в Центральном геологическом музее им. Ф. Н. Чернышева в Ленинграде.

\section{Л И ТЕРА Т У РА}

Макси мов а 3. А. 1962. Трилобиты ордовика и силура Сибирской платформы. Тр. ВСЕГЕИ, 76, вып. 5 .

Мянниль Р. М. 1958. Трилобиты семейств Cheiruridae и Encrinuridae из Эстонии. Тр. Ин-та геол. АН ЭССР, III.

Мянни и ь Р. 1970. Трилобиты рода Acernaspis из нижнего и среднего лландовери Эстонии. Изв. АН ЭССР, Хим. Геол., 19, № 2.

C a mpbel1 K. S. W. 1967. Trilobites of the Henryhouse formation (Silurian) in Oklahoma. Oklahoma Geol. Survey, Bull., 115.

Clarkson E. N. K. 1966. Schizochroal eyes and vision in some phacopid trilobites. Paleont., 9, pt. 3.

Lesperance P. J. 1968. Ordovician and silurian trilobite faunas of the White Head formation, Percé region, Québec. J. Paleont., 42, No. 3.

S t örmer L. 1940. Early descriptions of Norwegian trilobites. Norsk. geol. tidsskr., 20. We d e kind R. 1912. Klassifikation der Phacopiden. Deutsch. geol. Gesell., Zeitschr., 63.

$\begin{array}{cc}\text { Мнститут геологии } & \text { Поступила в редакцию. } \\ \text { Академии наук Эстонской ССР } & 10 / \mathrm{II} 1970\end{array}$

\section{REET MANNIL}

\section{EESTI ULEMLÄNDOUVERI FAKOPIIDID (TRILOBITA)}

Kirjeldatakse ülemländouveri liike Acernaspis? konoverenisis sp. n. ja A.? cf. konoverensis. Ländouveri fakopiidid on levinud peamiselt Kesk- ja Lōuna-Eesti savikates kivimites ja nende arengus on jälgitavad teatud kindlasuunalised morfoloogiliste tunnuste muutused.

\section{REET MATNNIL}

\section{PHACOPID TRILOBITES OF THE UPPER LLANDOVERIAN OF ESTONIA}

The present article is a continuation of the author's studies in Estonian phacopid trilobites (see Männil, 1970); it contains, apart from descriptions of Upper Llandoverian species, a discussion on the distribution and development of Estonian Llandoverian. Phacopidae. 
Acernaspis? konoverensis sp. $\mathrm{n}$.

(P1. I, Figs 1-9)

Anterior margin of cephalon widely rounded. Glabella inflated with almost vertical iront. Axial furrows slightly curved outwards with angle of divergence of approximately $50^{\circ}$ Glabellar furrows weakly impressed. Distal portion of anterior turrow situated at a small angle in respect to the axial furrow. The posterior border furrow of the cephalon divides the fixigena into two unequal parts in width (sag.). Eyes large, palpebral lobes wide, palpebral furrows very weak. Eye lenses placed in 17 vertical rows, their number amounting to $76-89$ in the specimens studied.

Vincular furrow absent anteriorly, notched laterally. Hypostomal suture convex backwards.

Pygidium widely rounded.

A similar species, $A$. orestes (Billings) differs from the species described by a more strongly curved anterior margin of the cephalon, by 16 vertical rows of eye lenses and existence of the continous vincular furrow. The Swedish Upper Llandoverian species Pterygometopidella quadrilineata (Ang.), according to available comparative specimens (Naturhistoriska Riksmuseet, Nr. Ar. 31365, 31387, 31388) differs from our species by a subangular anterior margin, flatter glabella, elongated cheeks, more clearly developed lateral border, 16 rows of eye lenses and a relatively long pygidium. It is possible that A.? konoverensis belongs to Pterygometopidella, but, since the type species of the latter genus has not been thoroughly examined and the diagnostic characters of the genus have not yet been preciseiy defined, we attribute, tentatively, our Upper Llandovery species to Acernaspis.

River Konovere, Lätiküla. Upper Llandovery, Adavere Stage (H)

\section{Acernaspis? cf. konoverensis}

(Pl. I, Figs 10-13)

Cephalon with a subangular anterior margin and a moderately inflated glabella. The angle of divergence of axial furrows $45-50^{\circ}$. Placement of glabellar furrows analogical to that of A.? konoverensis. Palpebral furrows clear. Eye lenses placed in 17 vertical rows. Posterior border furrow divides fixigena into two unequal parts in width (sag.)

Hypostomal suture transverse, vincular furrow absent anteriorly, laterally notched.

Pygidium relatively long, of a rounded-triangular shape.

The species described differs from $A$. ? konoverensis by a rather angular anterior part, flatter glabella, longer genal regions, stronger lateral borders and a longer pygidium. From Pterygometopidella quadrilineata it differs by a more inflated glabella, a straighter anterior margin and 17 vertical rows of eye lenses. It is possible that the form discussed is an independent species but until supplementary material is available, we prefer to name it conditionally as $A$. ? cf. konoverensis.

River Valgu, Upper Llandovery, Adavere Stage $(\mathrm{H})$.

The Estonian Llandoverian phacopid trilobites are mostly distributed in the argillaceous rocks of Central and South Estonia. In time, they are distributed from the Lower Llandoverian up to the lower part of the Wenlockian, with the following definitely outlined morphological changes: 1) at the beginning of the Llandoverian, all the species are supplied with a continuous vincular furrow, and the distal portion of the anterior glabellar furrow form an angle of about $45^{\circ}$ in respect to the axial furrow (Fig. 2, $a, \sigma, \varepsilon$ ); 2 ) in the species represented at the upper boundary of the Lower Llandoverian and in the Middle Llandoverian the vincular furrow is continuous, but weak anteriorly; in Middle Llandoverian species $A$. incerta the distal portion of the anterior glabellar furrow forms a smaller angle in respect to the axial furrow (Fig. 2, 2, $\partial$ ); 3) in Upper Llandoverian species, the vincular furrow is absent anteriorly, and the distal portion of the anterior glabellar furrow is almost parallel to the axial furrow (Fig. 2,e). The Wenlockian phacopid species not described in the present paper, are, on the whole, also subject to similar changes. 